\title{
NOTES
}

\section{Preparation of Polysilane/Gold Bilayer Using Polysilane/2-(Methylthio)ethyl Methacrylate Block Copolymer}

\author{
Yukihito MatsuURa, Hiroshi Inoue, and Kimihiro Matsukawa ${ }^{\dagger}$ \\ Osaka Municipal Technical Research Institute, 1-6-50 Morinomiya, Joto-ku, Osaka 536-8553, Japan
}

(Received February 23, 2004; Accepted May 7, 2004; Published July 15, 2004)

\author{
KEY WORDS Polysilane / 2-(Methylthio)ethyl methacrylate / Block Copolymer / Gold Surface / \\ Chemisorption / \\ [DOI 10.1295/polymj.36.560]
}

Polysilanes have been known as functional polymers with numerous electronic and optical properties such as photo-conductivity, electro- or photo-luminescence, etc., due to the $\sigma-\sigma^{*}$ conjugation of $\mathrm{Si}-\mathrm{Si}$ main chain which is confirmed by the conspicuous absorption band in the ultra-violet region. ${ }^{1,2}$ Organic-inorganic hybrid materials have also been known as promising materials for practical applications to electronic or optical devices. ${ }^{3,4}$ In order to improve some functionalities of polysilanes, we have prepared various polysilane-inorganic hybrid thin films in which polysilane segments are embedded in inorganic matrix such as silica, titania, and zirconia. ${ }^{5-10}$ Chujo has suggested that some chemical bonds or interactions between the organic and inorganic components are necessary to prepare homogeneous organic-inorganic hybrids. ${ }^{1-15}$ In our previous work, chemical bonds between polysilane-acrylic or -methacrylic block copolymers and inorganic components via sol-gel reaction are used for preparation of homogeneous polysilane-silica or -titania hybrid thin films. On the other hand, a chemisorption of organic compounds on a gold surface through a gold-sulfur interaction has been well studied to fabricate a self-assembled monolayer expected for molecular devices or biomaterials. ${ }^{16}$ Furukawa has reported polysilanes bearing sulfide tripod terminus, which was used for the selective chemisorption on a gold surface. ${ }^{17}$ In this report, we have synthesized a block copolymer of poly(methylphenylsilane) (PMPS) and 2-(methylthio)ethyl methacrylate (MTEM), P(MPS-co-MTEM), by photopolymerization using PMPS as a macro-photo-initiator and prepared a bilayer structure of P(MPSco-MTEM)/Au in which the copolymer adsorbed to gold layer. Furthermore, P(MPS-co-MTEM)/Au was applied to prepare gold colloids having the plasmon resonance absorption in visible region.

\section{EXPERIMENTAL}

\section{Polymerization}

P(MPS-co-MTEM) was synthesized by photopolymerization of MTEM with PMPS, as a macrophoto-initiator, of $M_{\mathrm{n}}=2.8 \times 10^{4}, \quad M_{\mathrm{w}} / M_{\mathrm{n}}=2.5$, $\lambda_{\max }=340.0 \mathrm{~nm}$. Toluene solution $(7 \mathrm{~mL})$ of PMPS $(1.0 \mathrm{~g})$ and MTEM $(1.0 \mathrm{~g})$, sufficiently degassed by a freeze-thaw method, was irradiated by a high pressure Hg lamp ( $\left.10 \mathrm{~mW} / \mathrm{cm}^{2}: 20 \mathrm{~min}\right)$, followed by reprecipitation from hexane $(300 \mathrm{~mL})$ to give P(MPS-coMTEM) as a white powder in $0.88 \mathrm{~g}$ yield: $M_{\mathrm{n}}=$ $8.3 \times 10^{3}, \quad M_{\mathrm{w}} / M_{\mathrm{n}}=1.6 ;{ }^{1} \mathrm{HNMR} \quad\left(\mathrm{CDCl}_{3}, \quad 300\right.$ $\mathrm{MHz}): \delta-0.9$ to $0.1\left(\mathrm{Si}-\mathrm{CH}_{3}\right), 0.8\left(\mathrm{C}-\mathrm{CH}_{3}\right), 1.8-2.0$ $\left(-\mathrm{CH}_{2}-\right), 2.1\left(\mathrm{~S}-\mathrm{CH}_{3}\right), 2.5\left(\mathrm{~S}-\mathrm{CH}_{2}-\right), 4.0\left(\mathrm{O}-\mathrm{CH}_{2}-\right)$; $\lambda_{\max }=334.4 \mathrm{~nm}$. The ratio of PMPS to MTEM $(x / y$ in Figure 1), estimated by ${ }^{1} \mathrm{H}$ NMR, was $63 / 21$.

\section{Film Preparation}

A gold-coating on a quartz as a substrate was carried out by sputtering with about $100 \mathrm{~nm}$ thickness. A P(MPS-co-MTEM) thin film was prepared by dipcoating tetrahydrofuran (THF) solution $(6.0 \mathrm{~mL})$ of P(MPS-co-MTEM) $(30 \mathrm{mg})$. After coating and drying at $90^{\circ} \mathrm{C}$, the substrates were soaked with THF to remove excess P(MPS-co-MTEM) which did not take part in bonding to the gold surface. Hereinafter, this sample was abbreviated as P(MPS-co-MTEM)/Au. The same experiment was carried out by using both PMPS on the gold layer and P(MPS-co-MTEM) on a quartz, which were respectively abbreviated as PMPS/Au and P(MPS-co-MTEM) $/ \mathrm{SiO}_{2}$.

\section{Characterization}

Characterization and investigation of the samples were carried out by using the following instruments. Gel permeation chromatography (GPC) was measured

${ }^{\dagger}$ To whom correspondence should be addressed (Tel: +81-6-6963-8123; Fax: +81-6-6963-8134; E-mail: kmatsu@omtri.city.osaka.jp). 


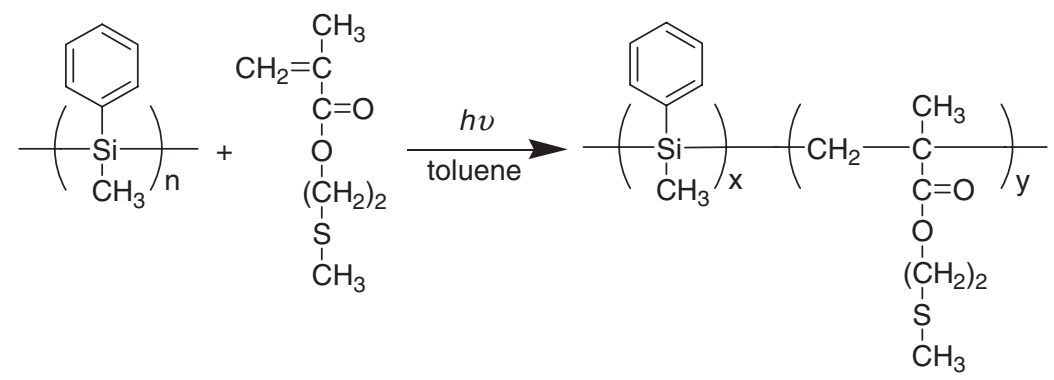

Figure 1. Synthesis of P(MPS-co-MTEM) by photopolymerization using PMPS and MTEM.

using a TOSOH HLC-8020, in which THF was used as the eluent and the calibration was done with polystyrene standards. ${ }^{1} \mathrm{H}$ NMR spectra was recorded by a JEOL EX-300 NMR spectrometer. UV-vis absorption spectra was measured by using a JASCO V-560. XRay photoelectron spectroscopy (XPS) was taken on a ULVAC Phi ESCA 5700. Height and phase images of atomic force microscopy (AFM) with a tappingmode were measured by a Digital Instruments Nanoscope IIIa.

\section{RESULTS AND DISCUSSION}

As shown in Figure 1, the polysilane copolymer, $\mathrm{P}(\mathrm{MPS}-\mathrm{co}$-MTEM), was prepared by photopolymerization. The composition ratio of PMPS and MTEM was $x / y=63 / 21$, calculated from analytical data of GPC and ${ }^{1} \mathrm{HNMR}$, and the UV absorption spectrum of copolymer indicated a $\sigma-\sigma^{*}$ absorption at around $330 \mathrm{~nm}$. A thin film of P(MPS-co-MTEM) on gold or $\mathrm{SiO}_{2}$ was prepared by dip-coating and soaking with THF to remove the excess copolymer.

From the UV absorption spectra after soaking with THF, PMPS/Au had no absorption peaks in the UV region as shown in Figure 2. And also, an extreme weak absorption at $330 \mathrm{~nm}$ was observed in the UV absorption spectrum of $\mathrm{P}(\mathrm{MPS}-\mathrm{co}-\mathrm{MTEM}) / \mathrm{SiO}_{2}$. PMPS could not make any interaction to the gold layer because PMPS has no functional groups to interact with the gold layer. Furthermore, the weak absorption peak at $330 \mathrm{~nm}$ of $\mathrm{P}(\mathrm{MPS}-\mathrm{co}-\mathrm{MTEM}) / \mathrm{SiO}_{2}$ showed the existence of mere trace amounts of P(MPS-coMTEM) on quartz surface. In contrast, P(MPS-coMTEM)/Au had a relatively strong absorption peak of $\sigma-\sigma^{*}$ absorption around $330 \mathrm{~nm}$ due to the $\mathrm{Si}-\mathrm{Si}$ main chain of PMPS. It was found that P(MPS-coMTEM) was adsorbed on gold layer due to a large amount of sulfide group in the copolymer, and the $\mathrm{P}(\mathrm{MPS}-\mathrm{co}-\mathrm{MTEM}) / \mathrm{Au}$ was a bilayer structure of P(MPS-co-MTEM) with gold. The P(MPS-coMTEM) layer on the gold surface was observed by the image of AFM as shown in Figure 3a, in which the boundary part between the copolymer and gold was represented. The surface of P(MPS-co-MTEM)/

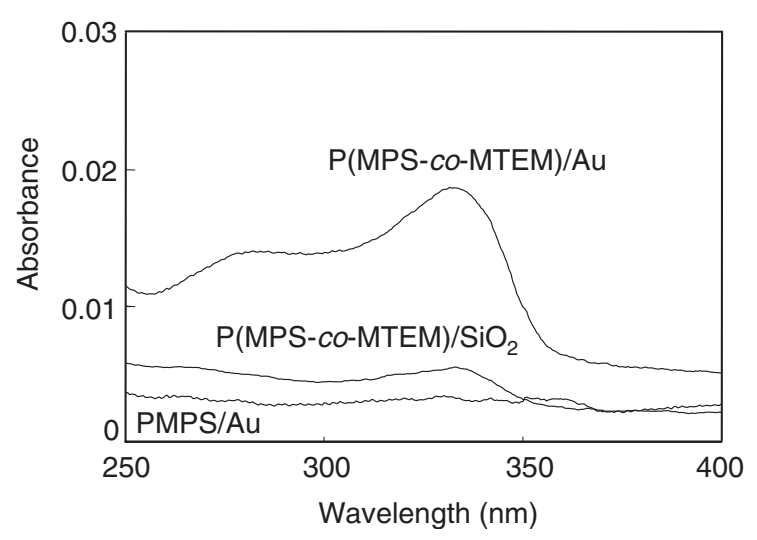

Figure 2. UV absorption spectra of P(MPS-co-MTEM) on a gold layer (P(MPS-co-MTEM)/Au), PMPS on a gold layer (PMPS/Au), and P(MPS-co-MTEM) on a quartz (P(MPS-coMTEM) $/ \mathrm{SiO}_{2}$ ), after soaking with THF. The absorption of the gold thin film was subtracted from the UV absorption spectra of $\mathrm{P}(\mathrm{MPS}-\mathrm{co}-\mathrm{MTEM}) / \mathrm{Au}$ and PMPS/Au.

(a)

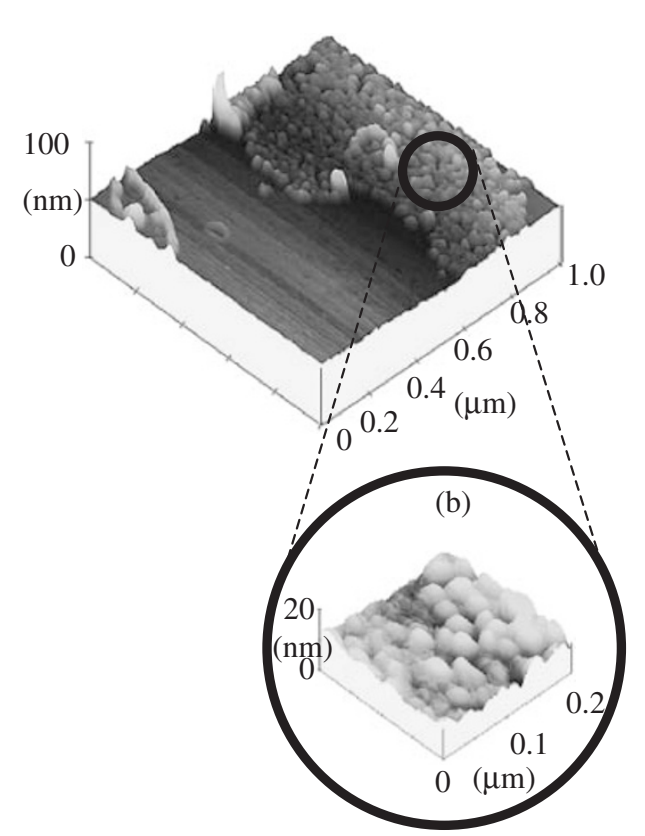

Figure 3. AFM images of P(MPS-co-MTEM)/Au (a) in a range of $1 \mu \mathrm{m} \times 1 \mu \mathrm{m}$ and (b) in a range of $200 \mathrm{~nm} \times 200 \mathrm{~nm}$. The range of height was (a) $100 \mathrm{~nm}$ and (b) $20 \mathrm{~nm}$. 


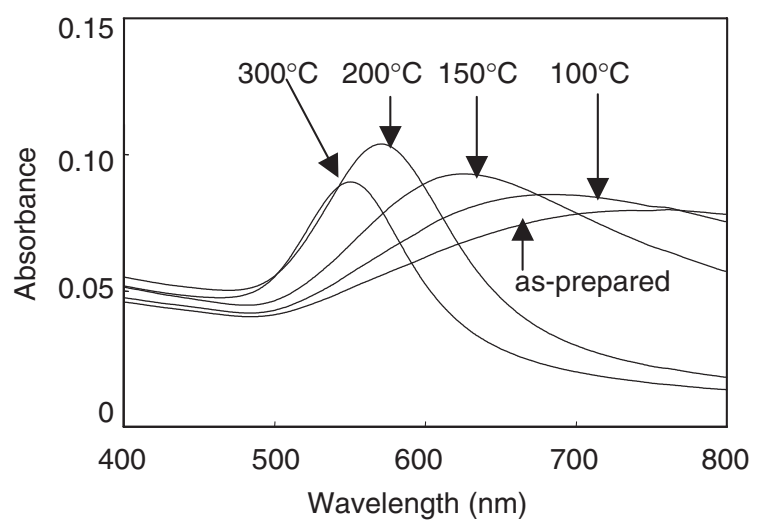

Figure 4. UV-vis absorption spectra of P(MPS-co-MTEM)/ Au after heating at $100-300^{\circ} \mathrm{C}$.

$\mathrm{Au}$ had numerous protrusions below $10 \mathrm{~nm}$ as shown in Figure $3 b$ (the magnified AFM image in a range of $200 \mathrm{~nm} \times 200 \mathrm{~nm}$ ). Existence of the polysilane segments on these ultrathin films $(<10 \mathrm{~nm})$ was confirmed by X-Ray photoelectron spectroscopy (XPS), because a strong $\mathrm{Si}_{2 p}$ peak at $102 \mathrm{eV}$ due to the $\mathrm{Si}-$ Si bond was observed in a spectrum of P(MPS-coMTEM)/Au. From these results, it was presumed that P(MPS-co-MTEM) provided a monolayer-like thin film on the gold surface.

A thermal treatment of P(MPS-co-MTEM)/Au was investigated, as it was reported that colloidal gold particles were generated at high temperatures in the presence of polysilane. ${ }^{18,19}$ Figure 4 shows a change of UV-vis absorption spectrum of P(MPS-co-MTEM)/ $\mathrm{Au}$ in a temperature range of $100-300^{\circ} \mathrm{C}$. An absorption peak around $600 \mathrm{~nm}$ due to the plasmon resonance of gold nanoparticles appeared at $150^{\circ} \mathrm{C}$ and shifted to $550 \mathrm{~nm}$ at $300^{\circ} \mathrm{C}$. This phenomenon was known to be arose by reducing the size of gold colloids. ${ }^{20}$ However, the PMPS thin film on the gold layer without THF-soaking indicated only a $10 \mathrm{~nm}$ blue shift under the same heating condition. This difference supports that a gold-sulfide interaction between P(MPS-co-MTEM) and gold provides smaller gold colloids compared to the PMPS thin film on the gold surface. And also, the formation of gold nanoparticles could be confirmed by XPS measurements, because the peak around $84 \mathrm{eV}$ due to $\mathrm{Au} 4 \mathrm{f}_{7 / 2}$ appeared after aging P(MPS-co-MTEM)/Au. This spectral change suggested that gold nanoparticles diffused into the polysilane copolymer.

\section{CONCLUSIONS}

P(MPS-co-MTEM) was synthesized by using MTEM with PMPS as a macro-photo-initiator for the photopolymerization, and the chemisorption of P(MPS-co-MTEM) on a gold surface provided a bilayer structure of $\mathrm{P}(\mathrm{MPS}-\mathrm{co}$-MTEM)/Au through a gold-sulfide interaction. This preparation method of polysilane/Au bilayer using P(MPS-co-MTEM) is greater facility than the other using polysilanes with terminal sulfur functional groups, because it was difficult to synthesize the end-capped polysilanes. ${ }^{17}$ Furthermore, P(MPS-co-MTEM)/Au was used for preparing gold nanoparticles by aging at temperatures higher than $150^{\circ} \mathrm{C}$. It was suggested that the gold-sulfide interaction played an important role to generating gold nanoparticles on the gold surface simply by heating, in contrast to a result of formation on polysilane pre-exposed by UV-light. ${ }^{18,19}$ Therefore, it was found that the chemisorption of P(MPS-co-MTEM) on the gold surface occurred effectively and gold was changed to nanoparticles by heating. Further investigations on the gold nanoparticle preparation with polysilane copolymers are currently in progress.

Acknowledgment. This work was partly supported by a Grant-in-Aid for Scientific Research (15360172) from the Japan Society for the Promotion of Science.

\section{REFERENCES}

1. R. D. Miller and J. Michl, Chem. Rev., 89, 1359 (1989).

2. R. D. Miller, Adv. Mater., 28, 1733 (1989).

3. D. A. Loy and K. J. Shea, Chem. Rev., 95, 1431 (1995).

4. J. Wen and G. L. Wilkes, Chem. Mater., 8, 1667 (1996).

5. K. Matsukawa, S. Fukui, N. Higashi, M. Niwa, and H. Inoue, Chem. Lett., 1999, 1073.

6. Y. Matsuura, K. Matsukawa, and H. Inoue, Chem. Lett., 2001, 244.

7. Y. Matsuura, K. Matsukawa, R. Kawabata, N. Higashi, M. Niwa, and H. Inoue, Polymer, 43, 1549 (2002).

8. Y. Matsuura, K. Kumon, N. Tohge, H. Inoue, and K. Matsukawa, Thin Solid Films, 422, 4 (2002).

9. Y. Matsuura, S. Miura, H. Naito, H. Inoue, and K. Matsukawa, J. Organomet. Chem., 685, 230 (2003).

10. Y. Matsuura, H. Inoue, and K. Matsukawa, Macromol. Rapid Commun., 25, 623 (2004).

11. Y. Chujo, E. Ihara, S. Kure, and T. Saegusa, Macromolecules, 26, 5681 (1993).

12. R. Tamaki, K. Samura, and Y. Chujo, Chem. Commun., 1998, 1131.

13. R. Tamaki and Y. Chujo, Chem. Mater., 11, 1719 (1999).

14. Y. Imai and Y. Chujo, Macromolecules, 33, 3059 (2000).

15. K. Kim, D. Keum, and Y. Chujo, Macromolecules, 36, 867 (2003).

16. A. Ulman, Chem. Rev., 96, 1533 (1996).

17. K. Furukawa, K. Ebata, H. Nakashima, Y. Kashimura, and K. Torimitsu, Macromolecules, 36, 9 (2003).

18. N. Nagayama, K. Itagaki, and M. Yokoyama, Adv. Mater., 9, 71 (1997).

19. N. Nagayama, T. Maeda, and M. Yokoyama, Chem. Lett., 1997, 397.

20. N. G. Khlebtsov, V. A. Bogatyrev, L. A. Dykman, and A. G. Melnikov, J. Colloid Interface Sci., 180, 436 (1996). 